\title{
Memórias e posições enunciativas na formação de professores para as séries iniciais do ensino fundamental*
}

\section{Enunciative memories and positions in teachers education for the initial grades of elementary school}

\author{
$\mathrm{Dr}^{\mathrm{a}}$. Silvania Sousa do Nascimento**
}

\section{RESUMO}

Este artigo visa identificar, através das memórias discursivas e das posições enunciativas de licenciandos em Pedagogia, os indicadores da construção de uma posição de professor autor. A metodologia de análise está calcada nas reflexões de Pêcheux (1999) e Foucault (2000). O universo analisado foi constituído de 121 portfolios, selecionados aleatoriamente de um universo de cerca de 268 licenciandos em Pedagogia matriculados nos anos de 2002 e 2005, nas disciplinas de Fundamentos de Ciências da Natureza e Metodologia do Ensino de Ciências Físicas. A análise dos portfolios das turmas indicam uma variação na posição discursiva dos licenciandos que aponta para uma progressiva construção de uma identidade docente.

Palavras-chave: formação de professores; memória discursiva; posição discursiva; Análise de Discurso; ensino de ciências.

\footnotetext{
ABSTRACT

This article aims at identifying, through the discoursive memories and enunciative positions of Pedagogy undengraduate students, the indicators of the construction of a teacher-author. The method of analysis is based on the reflections of Pêcheux (1999) and Foucault (2000). The universe studied consisted of 121 portfolios, selected randomly from 268 students in Pedagogy between 2002 and

* Apoio: Cnpq e Fapemig.

** Professora Associada do Departamento de Métodos e Técnicas de Ensino DMTE e do Programa de Educação da Faculdade de Educação UFMG. E-mail: silnascimento@ufmg.br
} 
2005, taking the Principles of the Science of Nature and Methodology of Physics Education subjects. The analysis of the portfolios of the classes indicates a change in the discoursive position of licensing pointing to a gradual creation of a professor identity.

Keywords: training teacher; discoursive memory; discoursive position; Analysis of Discourse; Science Education.

\section{Introdução}

Em 1998, 10 anos após a homologação de nossa nova constituição, o censo escolar registrou cerca de 800 mil matrículas em classes de alfabetização. Dessas matrículas, aproximadamente $36 \%$ corresponderam às crianças entre 7 e 9 anos (BRASIL, 2000). Mesmo que os dados mostrem uma ligeira baixa no número de matrículas, quase $8 \%$ a partir de 2003 , podemos dizer que o país enfrenta ainda o desafio de universalização de acesso das crianças à Educação Básica. Além do acesso, é necessário garantir uma educação de qualidade, principalmente para as camadas populares, que estavam ausentes do sistema formal de ensino. Nesse contexto, ensinar se torna um ofício que ultrapassa a transmissão de conteúdos para um grupo homogêneo socialmente destinado aos longos estudos, como mostra alguns estudos da profissionalização do professor das séries iniciais (NUNES, 2007). A prática desse profissional, principalmente nos grandes centros urbanos, reside em acolher e garantir o sucesso de grupos de crianças de múltiplos horizontes culturais e que, muitas vezes, não vislumbram uma longa permanência no sistema educativo formal.

Nesse sentido pensar a formação do professor coloca em questão a integração de conteúdos técnico-científicos, como também didático-metodológicos de diferentes campos disciplinares, todos visando à promoção nos sujeitos de hábitos, entre outros, de leitura e de escrita. A formação inicial de professores para as classes de alfabetizações tem vivenciado, nos últimos anos, inúmeras mudanças. O Decreto Presidencial número 3.276, de 6/12/99, inicia um longo processo de inovações curriculares, principalmente nos cursos universitários de Pedagogia que assumem, em grande parte, a licenciatura para as séries iniciais do ensino fundamental. Nas muitas mudanças observadas no contexto da construção de projetos pedagógicos para essa formação destacarei, neste artigo, a disciplina que aborda o conteúdo de Ciências Físicas em duas versões curriculares do curso de Pedagogia da Faculdade de Educação da Universidade Federal de Minas Gerais - UFMG.

Essa disciplina foi obrigatória para as habilitações de Alfabetização e 
Educação de Jovens e Adultos - EJA - nas propostas curriculares do curso no período de desenvolvimento desse estudo. Ela era precedida por outra disciplina, obrigatória para todas as demais habilitações, de Fundamentos e Metodologia de Ciências Naturais e assim compunham, juntamente com outra de Ciências Biológicas, um conjunto de 180 horas voltadas para a formação em ciências da natureza desses pedagogos.

Neste trabalho não buscaremos uma diferenciação entre a alfabetização e o letramento científico. Chassot (2000, p. 34) considera a alfabetização científica, "[...] o conjunto de conhecimentos que facilitariam aos homens e mulheres fazer uma leitura do mundo onde vivem". Essa posição se aproxima da discussão sobre o sentido do letramento científico que toma, para o âmbito das ciências, as capacidades de ler e escrever sobre as ciências. Santos e Mortimer (2001) afirmam que o letramento científico passou a ser a principal meta do ensino de ciências em contraposição aos movimentos das décadas de 1950 e 1960 que defendiam a preparação de jovens para agirem socialmente como cientistas ou seguirem, futuramente, uma carreira científica. Preferimos nos aproximar das considerações sobre uma educação cidadã, como defende Morin (2008), na qual os sujeitos "alfabetizados" são aqueles capazes de codificar e decodificar o mundo, enquanto os letrados, dominando a prática social do código, são capazes de transformá-lo! Essa relação entre alfabetização científica, educação científica e exercício pleno da cidadania também é feita por outros autores como Krasilchik e Marandino (2006), Caruso (2003), Lorenzetti e Delizoicov (2001). A proposta das disciplinas, aqui analisadas, está na vertente de promover, nos futuros professores, a constituição de um repertório de práticas sociais de leitura e escrita constitutivas de uma cultura científica.

A pesquisa sobre a formação de professores para as primeiras séries do ensino fundamental, como destaca Carvalho (2002), versa sobre todas as facetas do ensinar, assim como sobre a reflexão dos professores sobre seu ensino. Para essa pesquisadora, mesmo tendo objetivos diferentes, essas facetas da pesquisa são importantes e necessárias para a melhor compreensão dos processos de aquisição do conhecimento físico. Outra vertente da pesquisa investiga os dispositivos formativos de professores. Altet pesquisou diferentes dispositivos de formação de professores na França e fez uma análise sobre os possíveis modelos de formação subjacentes (ALTET, 1994, p. 26). Segundo a autora, o modelo predominante na Antiguidade era aquele onde o "professor sabe" e, assim, não necessitava de uma formação, pois seu carisma nato era suficiente para possibilitar a "transmissão de conhecimentos". Com a criação das primeiras escolas de formação aparece um segundo modelo que se apoiava na transmissão de uma prática. A formação de professores foi baseada então na observação e na imitação da ação de um professor modelo, sendo o estágio o momento onde o "expert" supervisiona a ação do "noviço". Superando esse modelo, a formação de professores buscou suportes 
teóricos nas ciências humanas para racionalizar os dispositivos educativos e tratar a formação pela aquisição e aplicação de conhecimentos de ciências afins - psicologia, sociologia, filosofia, entre outras. A prática do professor era considerada semelhante à do engenheiro ou à do médico clínico, onde a vivência cotidiana superava a construção teórica dessas ciências afins. Nos últimos anos, apareceu o modelo de formação do professor reflexivo que analisa sua prática de uma forma dialética. Este profissional é capaz de refletir sobre sua prática, de resolver problemas e de criar novas estratégias de ensino. Nesses dois últimos modelos, a formação inicial é fundamental para fornecer não somente um referencial teórico para a análise da prática, mas também fornecer instrumentos de reflexão sobre a vivência cotidiana do professor.

Buscamos identificar, através das memórias discursivas e das posições enunciativas de licenciandos em Pedagogia, os indicadores da construção de uma posição de professor autor, que definiremos ao longo deste texto. Questionamos se há evidências do que podemos chamar de "objetivismo pedagógico", isto é, a realidade de sala de aula é formada por objetos que apresentam propriedades fixas. Os objetos podem ser descritos com precisão de detalhes definidos por um "expert" exterior ao processo de aprendizagem em sala de aula. Como indicador desse objetivismo pedagógico, consideramos a presença de um discurso prescritivo exterior ao processo de ensino e aprendizagem e à sala de aula. Buscaremos identificar tal exterioridade pelas posições enunciativas, no caso buscando uma posição de "professor autor", assumidas pelos licenciandos na materialidade discursiva analisada.

\section{Memória discursiva e posição enunciativa}

Para Pêcheux, a memória não pode ser entendida no sentido psicológico de uma memória individual, mas nos sentidos entrecruzados da memória mítica, da memória social inscrita em práticas, e da memória construída do historiador (PÊCHEUX, 1999, p. 50). O autor destaca que há uma tensão contraditória no processo de inscrição do acontecimento, que escapa, que não chega a se inscrever, e aquele acontecimento que é absorvido na memória que, por sua vez, pode ser considerado como se não tivesse ocorrido. A inscrição em um espaço de memória remete a diferentes formas de registros que possuem uma materialidade discursiva complexa. Ainda segundo Pêcheux, a memória discursiva possibilita que, diante de um texto que surge como acontecimento a ler, seja estabelecido os "implícitos" - os pré-construídos, os elementos citados e relatados, discursos transversos, entre outros. A leitura de uma materialidade discursiva implica na interpretação desses elementos "ausentes por sua presença" que definem a 
legibilidade de um discurso.

Foucault (2000, p. 9), enfrentando essa tensão contraditória de ler o não dito, supõe que:

em toda sociedade a produção do discurso é ao mesmo tempo controlada, selecionada, organizada e redistribuída por certo números de procedimentos que têm por função conjurar seus poderes e perigos, dominar seu acontecimento aleatório, esquivar sua pesada e temível materialidade.

Em seu texto sobre a ordem do discurso, esse autor descreve alguns procedimentos de controle e de delimitação do discurso que, de certo modo, são exteriores ao discurso e funcionam como sistemas de exclusão de sentidos. Outros procedimentos são colocados como interiores, visto que os discursos possuem internamente procedimentos que funcionam, sobretudo, a título de princípio de classificação, de ordenação e de distribuição de significados. Dessa forma, para Foucault (2000, p. 22),

\begin{abstract}
Em suma, pode-se supor que há, muito regularmente nas sociedades, uma espécie de desnivelamento entre os discursos: os discursos que "se dizem" no correr dos dias e das trocas, e que passam com o ato mesmo que os pronunciou; e os discursos que estão na origem de certo número de atos novos de fala que os retomam, os transformam ou falam deles, ou seja, os discursos que, indefinidamente, para além de sua formulação são ditos, permanecem ditos e estão ainda por dizer.
\end{abstract}

Nessa vertente da Análise de Discurso, a materialidade do discurso insere um efeito de opacidade decorrente de um jogo metafórico entre a memória discursiva e o acontecimento. Dessa forma, a análise tende a distanciar-se das evidências de proposições, frases e paráfrases, para buscar interrogar na montagem de sequências discursivas as significações e suas condições implícitas de interpretação. Assim, a análise busca não o novo significado que está no que é dito, mas no acontecimento de sua volta recortado indefinidamente por outros discursos.

Foucault em sua obra vai destacar o autor, princípio de agrupamento do discurso, unidade e origem de suas significações e foco de sua coerência, a partir de uma posição assumida que recortará "na inquietante linguagem da ficção suas 
unidades, seus nós de coerência, sua inserção no real" (FOUCAULT, 2000, p. 28). Para Orlandi (1988), autor é o sujeito que assume uma posição enunciativa diferente de falante ou enunciador, pois domina procedimentos discursivos internos e externos. Na Análise de Discurso, a posição enunciativa, repertoriada por Charaudeau e Maingueneau (2004) como "posicionamento", diz respeito à instauração e à conservação de uma identidade enunciativa. Designamos a posição enunciativa à forma como o locutor, por meio de emprego de registros linguísticos e de uma escolha de gêneros, indica como ele se situa no espaço conflituoso do acontecimento discursivo. Compartilhamos do pressuposto colocado por Nuernberg (2002) de que a fala do sujeito realiza-se a partir de uma posição enunciativa determinada, de acordo com o contexto do qual ele participa ou se exclui.

Em resumo, nosso questionamento é em relação ao estabelecimento de uma memória discursiva e de alterações nas posições enunciativas de licenciandos de Pedagogia ao trabalharem em uma disciplina de ensino de Ciências. Em relação à memória discursiva o esperado é a criação de um interdiscurso reflexivo com os diversos textos teóricos trabalhados em sala de aula como um indicador de uma apropriação de um quadro analítico da ação pedagógica, isto é, de procedimentos externos ao discurso. As alterações na posição discursiva, por sua vez, poderiam ser consideradas indicadores de uma mudança da posição de aluno receptor de informações, passando assim, a dominar o controle de significado em procedimentos internos: a ordenação, a classificação; e externos: delimitação e pertinência do discurso da ciência escolar. Assim o licenciando assumiria uma posição de autor.

\section{A análise}

\section{O contexto da disciplina de Metodologia de Ciências Físicas}

O objetivo principal da disciplina analisada era discutir alguns fenômenos físicos e químicos, algumas leis gerais para a explicação de transformações físicas e químicas e aspectos cognitivos da construção de explicações causais nas crianças de 6 a 10 anos. Nas sessenta horas de curso, os licenciandos construíram dispositivos de ensino aplicáveis aos primeiros anos de escolarização e analisaram artigos de pesquisa sobre a educação em ciências. As manipulações experimentais, quando presentes, foram organizadas na própria sala de aula não 
sendo comum o uso de laboratório didático. Algumas delas foram programadas para desenvolver, nos licenciandos, habilidades próprias do "fazer ciências" passíveis de serem aplicadas em classes de alfabetização. A bibliografia básica do curso foi bastante diversificada tendo como orientador o livro de Carvalho et al (1998). Um objetivo maior das disciplinas oferecidas nos anos analisados foi a discussão de uma cultura científica aliada ao desenvolvimento, nas classes de alfabetização, de uma cultura de ler e escrever em ciências. Assim, no decorrer da disciplina um conjunto de dispositivos didáticos proposto como tarefas individuais ou de grupo versou sobre esse tema. Neste artigo pretendemos analisar o registro escrito dos licenciandos apresentado na forma de um portfolio avaliativo entregue ao final das disciplinas. O portfolio é aqui tomado como um registro individual e regular, organizado cronologicamente em uma pasta, caderno ou fichário, de toda a produção escrita do licenciando. A orientação era de construílo, semanalmente, ao longo das disciplinas, o que poderia gerar uma progressão tanto na forma de registrar as tarefas quanto na reflexão das mesmas. A proposta trabalhou com a hipótese de um avanço progressivo na forma de registro e da produção de uma memória discursiva, assim como de alterações nas posições enunciativas dos licenciandos na medida que um quadro teórico lhes era apresentado. O resultado obtido mostra uma grande criatividade dos licenciandos, em geral mulheres, ao produzirem seus portfolios em formatos diversos, desde aqueles mais acadêmicos registrados em cadernos de laboratório aos ilustrados que se aproximam dos cadernos de ciências das classes de alfabetização.

\section{O conjunto de portifólios e a metodologia de análise}

O universo aqui analisado foi constituído de 121 portifólios selecionados aleatoriamente de um universo de cerca de 268 licenciandos em Pedagogia matriculados nos anos de 2002 e 2005, nas disciplinas, de duas versões curriculares distintas, de Fundamentos de Ciências da Natureza e Metodologia do Ensino de Ciências Físicas. Para aprofundar a análise do contexto de produção desses documentos, analisaremos 27 portfólios das turmas da disciplina de Fundamentos e Metodologia de Ciências Naturais, obtidos de forma aleatória por solicitação aos alunos matriculados na disciplina de Ciências Físicas em 2002. Dois professores estavam envolvidos nessas disciplinas e neste artigo os nomeamos de João e Lúcia. A coleção que constitui o corpus foi organizada como mostra o Quadro 1. 


\begin{tabular}{|c|c|c|c|c|}
\hline $\begin{array}{c}\text { Semestre } \\
\text { e ano }\end{array}$ & Disciplina & Professor (a) & $\begin{array}{c}\mathrm{N}^{\circ} \text {. licenciandos } \\
\text { matriculados }\end{array}$ & $\begin{array}{c}\mathrm{N}^{\circ} \text {. portfólios } \\
\text { analisados }\end{array}$ \\
\hline $1 / 2002$ & $\begin{array}{c}\text { Fundam. e metodologia de } \\
\text { Ciências da Natureza }\end{array}$ & João/Lúcia & 131 & 27 \\
\hline $2 / 2002$ & $\begin{array}{c}\text { Fundam. e metodologia de } \\
\text { Ciências Físicas }\end{array}$ & Lúcia/João & 63 & 45 \\
\hline $2 / 2005$ & $\begin{array}{c}\text { Fundam. e metodologia de } \\
\text { Ciências Físicas }\end{array}$ & Lúcia & 74 & 49 \\
\hline & TOTAL & & 268 & 121 \\
\hline
\end{tabular}

QUADRO 1- ORGANIZAÇÃO DA COLEÇÃO DE PORTFOLIOS

Nossa análise foi constituída da leitura sistemática de cada grupo de portfolios buscando interpretar os indícios de entrecruzamentos de memórias discursivas e a alteração na posição enunciativa dos licenciandos. Dessa forma, não temos uma análise discursiva nos formatos da pragmática, onde as unidades de análises são pré-definidas. Ao contrário, a interpretação do discurso relatado nos portfolios nos indica algumas direções de interpretações que discutiremos a seguir.

Não podemos esquecer que o contexto de produção desses discursos é avaliativo e, assim, os licenciandos deveriam priorizar certas posições enunciativas que valorizavam o discurso do professor na busca de uma aprovação. Logo, estamos mais interessados nos silenciamentos do que na verificação da presença ou ausência de um discurso científico. Discutiremos nossa análise criando uma narrativa cronológica das disciplinas colocando excertos de portfolios ilustrativos da produção dos licenciandos.

\section{A disciplina de Fundamentos e Metodologia de Ciências Naturais}

Essa disciplina foi oferecida em 2002 pelos professores Lúcia e João em quatro turmas (turnos manhã e noite). O registro de sua ementa foi: diretrizes curriculares para as Ciências Naturais no Ensino Fundamental. Objetivos, conteúdos, metodologias, linguagem e processos de apropriação. Natureza das Ciências Naturais e implicações para a prática docente. O programa distribuído aos licenciandos contemplava os fundamentos epistemológicos e psicológicos do ensino de Ciências, sua relação com a prática escolar e a construção de sequências de ensino. O livro de Bizzo (2000) foi indicado como texto básico e, o início do curso foi relatado com destaque para a organização da disciplina, 
principalmente o formato da avaliação, e uma posição enunciativa já na primeira pessoa do plural. Esta disciplina se encontra, na grade curricular, em um momento que a turma já possui uma identidade coletiva formada. Abaixo temos dois excertos, característicos desse grupo de portfolios, nos quais destacamos o estabelecimento de uma narrativa bem marcada temporalmente por advérbios (primeiramente, após e depois) e inteiramente construída na primeira pessoa do plural, ou seja, uma posição enunciativa de grupo.

No primeiro exemplo podemos ver o movimento de passagem de uma posição de recepção de informação (foi nos apresentado... Após esclarecer todos os pontos... chega para nós) para a participação coletiva (observamos... percebemos... chegamos a conclusão...).

\section{8/01 - $1^{\mathrm{a}}$. Aula}

Primeiramente foi nos apresentado o programa de curso e a proposta de avaliação, inclusive sobre este portfolio. Após esclarecer todos os pontos e tirar as dúvidas, o professor pediu para que desenhássemos um cientista. [imagem do cientista].

Após todos desenharem, observamos os desenhos e percebemos semelhanças como: óculos, guarda-pó, cabelo despenteado, utensílios de laboratório. E depois de algumas discussões chegamos à conclusão que todos nós vemos o cientista como um estereótipo e vimos que essa imagem de cientista maluco chega para nós desde criança. (14-102)

No segundo excerto, destacamos um exemplo que também apresenta como indícios uma marca temporal (quando terminamos, após essa atividade) e uma posição coletiva (percebemos), mas uma posição de primeira pessoa (posso concluir) reportando ao coletivo (de nós).

28/01

Avaliação da atividade:

[imagem do cientista]

Quando todos terminamos de fazer o desenho, a professora perguntou como havíamos desenhado o cientista. Foi interessante porque percebemos que tínhamos (a maioria) a mesma concepção de cientista: vestido com um jaleco, usando óculos, os cabelos sem arrumar, com algum tubo de ensaio na mão e com substâncias saindo fumaça. Telescópios e outros. Essa concepção de cientista apresentada por nós também aparece em uma pesquisa feita em outro país, sobre como as pessoas imaginam um cientista. 
Após essa atividade e as discussões feitas em sala posso concluir que a ciência parece ser uma fonte de conhecimento muito distante de nós. (20-102)

Esses indícios não aparecem neste próximo excerto, onde o licenciando tomou a mesma atividade como um teste.

\section{8/01 Teste}

Desenho baseado na minha concepção de cientista que é transmitida não só na escola, nos livros, mas também nos veículos de comunicação.

[imagem do cientista] (26-102)

Os indícios de memória discursiva aparecem, nos portfolios, de diferentes formas materializadas como lembranças das aulas, dos professores... como no excerto a seguir:

$28 / 01$

Discussão do que é ciências, o que abrange, lembranças das aulas de ciências, etc.

Desenhar um cientista:

[imagem do cientista]

A discussão foi muito interessante, lembramos de algumas aulas que tivemos no passado, de alguns professores, etc.

Ao compararmos os desenhos de cientistas vimos que a maioria possui basicamente as mesmas características, ou seja, temos a mesma visão do que é um cientista. (25-102)

As atividades de leitura de textos, no portfolio, são registradas de forma bastante homogênea, tendo prioridade um formato de resumo marcado pela presença do autor do texto como no excerto a seguir:

$18 / 02$

Segundo Bizzo o papel no ensino de ciências não é o de preparar novos cientistas no meio de uma multidão de alunos. Tempos atrás o ensino de ciências seria para poucos e para a grande maioria era apenas uma espécie de "placebo pedagógico". (10-102) 
Um destaque especial é o formato prescritivo presente, como no exemplo a seguir, quando o discurso é dirigido a uma terceira pessoa: o professor. Nesse caso, podemos supor que o licenciando se posiciona como o especialista exterior que organiza a ação do professor.

03/03

O professor deve evitar testar muito, os seus alunos, para não criar neles uma baixa auto-estima. Pois se tudo for contrário ao que ele pensa como vai ficar? (16-102)

A disciplina trabalhou com diferentes gêneros de textos e dinâmicas para provocar mudanças na posição enunciativa dos licenciandos, uma delas, explicitada no excerto a seguir, a partir da leitura de um dos capítulos do livro adotado foi construído, em grupo, um cartaz com palavras chaves que representavam as ideias centrais do texto.

03/03

A atividade tem uma dinâmica diferente da maneira como normalmente se trabalha em sala de aula, porque além de não ser uma tarefa monótona, conta com um momento de socialização com todos os grupos, e isso, para mim, foi muito rentável porque pude perceber, através da explanação dos colegas, alguns aspectos que tinha não (sic) passado despercebido no momento da leitura. (23-102)

Outro exemplo, que destacamos, foi o exercício de escrever uma carta para uma professora distante, justificando, segundo os argumentos do texto, a importância de ensinar ciências nas turmas de alfabetização.

Belo Horizonte, 28 de fevereiro de 2002

Querida Bia,

Como vão as coisas aí em Jacuri? Aqui as coisas estão legais. Estou com saudades, porém a correria é muita. Tenho muitas idéias para poder te passar, estou cursando Pedagogia e tenho me lembrado muito de você.

Este semestre estou ( $\mathrm{sic}$ ) tendo aulas de ciências e li um texto que tem tudo haver com que você está passando aí com sua escola. (11-102) 
As novas formas de trabalhar com os textos em sala de aula podem ter promovido mudanças nas posições enunciativas, fato que observamos nas avaliações finais do portfolio como a seguir.

$26 / 05$

Na minha concepção o curso de uma forma geral foi de muita valia. A metodologia utilizada pelo professor é interessante, motivadora, os recursos usados $f a z$ (sic) a diferença, a forma como as aulas foram ministradas fez com que debatêssemos, questionássemos. Com isso consegui, no decorrer das atividades, assimilar conhecimentos, que antes não conhecia. (09-102)

\section{A disciplina de Fundamentos e Metodologia de Ciências Físicas}

Os portfolios que analisamos dessa disciplina são oriundos de 2 períodos diferentes, nos quais os alunos tiveram, anteriormente, os mesmos professores, Lúcia e João, na disciplina de Ciências Naturais. Para esta disciplina, analisamos um conjunto de 94 portfolios de um universo de cerca de 137 licenciandos matriculados. A disciplina foi ofertada para uma única turma, por turno. O programa da disciplina deu ênfase aos princípios epistemológicos e psicológicos do ensino de Ciências Físicas e as atividades de conhecimento físico. As marcas de continuidade da metodologia de ensino das disciplinas ficam bem evidenciadas no discurso dos licenciandos, lembrando que isso pode ter sido considerado, por eles, como fator para a avaliação positiva do portfolio. Como destacado no excerto abaixo, é raro o licenciando que aponta elementos negativos ao desenvolvimento da disciplina.

23/05/05

Reflexão do curso Fundamentos e Metodologia de Ciências Físicas

Não é a primeira vez que tenho aula com a professora Lúcia. Então já estava acostumado com sua metodologia.

Achei muito bom o andamento do curso e como foi ministrado todo conteúdo programático. (42-205) 
Nessa disciplina como na anterior, veja no próximo excerto, uma memória importante é aquela do livro texto adotado de Carvalho et al (2000) o que, de certo modo, é o esperado.

\section{$24 / 06 / 02$}

As atividades da disciplina de Fundamentos e Metodologia do Ensino de Ciências Físicas tiveram início com a apresentação do fichamento do livro "Ciências no Ensino Fundamental". O texto lido da autora Anna Maria Pessoa de Carvalho trouxe-nos as pesquisas realizadas, no sentido de melhor conhecermos como ensinar a matéria a crianças de sete a dez anos de idade. (14-202)

Os indícios da primeira pessoa do singular estão presentes nestes portfolios como nos outros, nos depoimentos finais, e, em particular, a posição em relação à disciplina de física aparece, em geral, como a seguir:

\section{$23 / 05 / 05$}

Sobre a relação de massa e energia, confesso que ainda persistem algumas dúvidas. Na verdade, a física sempre foi o meu ponto fraco, e quanto mais aprofundamos sobre os temas, mais eu me perco. Embora eu tenha procurado me inteirar sobre o assunto em outras fontes, não me sinto capaz de dar uma aula sobre isso. Graças a Deus tenho buscado me especializar em educação infantil, onde acredito não precisarei dominar estes conceitos. (49-205)

Esta disciplina possuía como proposta a observação de fenômenos astronômicos, além de atividades de conhecimento físico previstas no livro texto. Os indícios de memória discursiva aparecem, nos portfolios, de diferentes formas como no excerto a seguir,

\section{4/08/02}

Um terceiro momento da aula foi a proposição de um problema pela professora Lúcia. Cada grupo recebeu um pequeno globo terrestre, um copinho plástico como suporte e o desafio de posicionar esse globo em relação aos pontos cardeais, tomando como referência a nossa posição na Terra (Hemisfério Sul, Brasil). Iniciamos também hoje a observação da lua (fase cheia até a próxima fase cheia) (01-202) 
A conclusão da atividade de observação de uma lunação foi assim relatada:

$19 / 09 / 02$

Encerramento do período de observação da Lua.

Dentro do roteiro proposto e da nossa disponibilidade conseguimos verificar o seguinte: com o passar dos dias a sensação ou melhor a idéia é que a Lua anda mais devagar que o Sol, pois a cada dia a Lua atrasava um pouquinho o seu "nascimento". Na Lua Cheia - visualização completa da Lua, o próprio nome diz lua cheia -, nasce a tardinha e fica a maior parte do tempo em exposição no período noturno. No início do nascimento por volta das 18:00 horas e ocaso, por volta das 6:00 h. (06-202)

Podemos observar, nos discursos dos licenciandos, a dinâmica da disciplina destacando as tarefas a cumprir.

$22 / 07 / 02$

A professora Lúcia solicitou-nos ainda, que nos dirigíssemos mais uma vez ao pátio da universidade, a fim de verificarmos a mudança de posição das sombras dos representantes de cada grupo. Para tanto, riscamos no chão com giz, marcando o horário de cada posição diferente. Foi muito bom realizar essa tarefa, espero que no decorrer do curso haja outras como esta! (10-202)

Nesta disciplina um livro para-didático para crianças foi trabalhado em sala de aula. O registro da leitura desse trouxe a marca do formato de resumo e com diferentes argumentos de não recomendação de leitura desse livro pelas crianças, assumida como posição do grupo, como no excerto a seguir.

05/08/02

Concluímos que o livro não é muito indicado para crianças lerem e sim para uso didático, ou seja, é um material de uso do professor. O livro é um pouco complexo, traz vários conceitos e acaba trazendo uma metodologia de ensino para ser usado (sic) com as crianças. (08-202) 
As atividades experimentais foram registradas em um formato relatório experimental, mesmo quando as mesmas não foram apresentadas em um formato de protocolo experimental escolar.

01/07/02

Atividade do submarino

Usar os conhecimentos prévios para formular hipóteses. Deixar que errem, o erro ajuda o aluno a pesquisar mais. $\mathrm{O}$ trabalho em grupo é muito rico, são várias hipóteses. Ao terminar, as crianças devem tentar explicar como realizaram a experiência e para quê obtiveram tal resultado. Por fim, é recomendável que relacionem a experiência com o cotidiano. (09-202)

Destacamos o formato prescritivo presente, no exemplo acima, e, nesse caso, podemos supor que o licenciando se posiciona como pedagogo ou faz um tipo de indicativo da ação do professor. Os licenciandos identificaram muito rapidamente um formato prescrito de protocolo experimental e adotaram uma posição impessoal nos registros das aulas experimentais. Podemos supor que o fato de ter esse tipo de atividade tenha despertado uma memória do discurso científico tido como impessoal e geral.

\section{Discussão dos resultados}

Nossa amostra representa um pequeno conjunto da produção desses licenciandos em Pedagogia. Em virtude das diversas alterações curriculares que essa licenciatura vem passando, não nos preocupamos em estabelecer uma amostra cronológica dos portfolios, mas sim coletar, em dois momentos da mesma disciplina, aspectos da memória discursiva e da posição enunciativa registrada em um texto avaliativo. Analisamos inicialmente o conjunto daqueles oriundos da disciplina de Ciências Físicas, nosso principal foco. Ao percebemos os indícios de continuidade nas posições marcadas pela presença do professor, aprofundamos a análise de produções da disciplina de Ciências Naturais anterior ao curso. Como podemos observar, os licenciandos, no decorrer dessa primeira disciplina, já assumem uma posição enunciativa de grupo marcada por indicadores de uma narrativa temporal. Isto pode indicar que os licenciandos já dominam procedimentos internos ao discurso, posicionando corretamente temporalmente no momento avaliativo. Em nossa pequena amostra da primeira disciplina, a 
memória discursiva é presente em um diálogo que não ultrapassa o livro texto. Isto nos questiona sobre o silêncio dos outros textos, na forma de leituras complementares, sempre presentes na formação inicial de professores. Por que esses licenciandos não arriscam o registro de um diálogo com todo o universo de autores que tem acesso? Será que podemos inferir um não posicionamento de autores em relação a esse universo de leitura? Será que nossos licenciandos não constroem uma materialidade discursiva no decorrer da formação?

Podemos pensar que, por se sentirem inseguros com o conteúdo ou por se tratar de um momento avaliativo, priorizaram a voz de autoridade: do livro ou do professor. Já na segunda disciplina, observamos manifestações explícitas do pouco domínio dos procedimentos externos ao discurso de sala de aula, neste caso, marcado pelo discurso da rejeição da "física escolar". Esta posição é uma marca forte de posicionamento, onde a autoria é mais evidenciada. Lamentavelmente esse momento forte do registro mostra mais uma tensão entre o domínio dos procedimentos internos e externos dos discursos que circulam nessas disciplinas. De um lado, o discurso da "ciência escolar" que povoa a memória individual e coletiva dos licenciandos promovendo interdiscursos lacunares sobre os conteúdos de conhecimento físico tratados enquanto conteúdo disciplinar. O compartilhamento de lacunas e do imaginário da ciência coadunam com várias pesquisas nacionais sobre o ensino de Ciências nas séries iniciais (PAVÃO; FREITAS, 2008). E, de outro lado, um objetivismo pedagógico afasta o licenciando da sala de aula e o coloca na posição de "expert" que prescreve a ação do professor. Nesse caso temos um novo perfil de autoria que visa controlar, selecionar e redistribuir o significado do discurso. Nossa hipótese de uma progressão na posição enunciativa visando à construção reflexiva não foi confirmada. Consideramos que a situação de produção não favoreceu o registro de tal progressão principalmente pela ausência de enunciação de uma tarefa relacionada a isso. A prática de portfolios tem favorecido o registro narrativo do percurso didático sem problematizar a memória discursiva. Dessa forma, os licenciados reproduzem o que julgam ser elemento avaliativo relevante: a voz do livro texto e do professor. Questionamos se a alternância entre uma posição de professor e de pedagogo não provoque este silêncio do procedimento interno ao discurso da sala de aula do ensino superior, onde o objeto de ensino não é o conteúdo de ciências, mas o dispositivo de ensinar ciências. Os licenciandos, talvez, se posicionem como alunos de ciências e não professores em formação e busquem dominar os procedimentos de aprender ciências e não de ensinar ciências. Este resultado aponta, mais uma vez, para o contexto de nosso ensino de ciências na Educação Básica.

Estas primeiras conclusões nos estimulam a perseguir a possibilidade de formar professores autores de um discurso do ensinar e aprender ciências. 


\section{REFERÊNCIAS}

ALTET, Margaret. La formation professionnelle des enseignants. Pedagogie d'aujourd'hui. Paris: Presse Universitaire Française, 1994.

BIZZO, Nélio. Ciências: fácil ou difícil? São Paulo: Ática, 2000.

BRASIL. Sinopse estatística da educação básica. Censo Escolar. INEP.MEC: Brasília, 2000. Disponível em: <http://www.inep.gov.br/download/censo/1999/basica/ SINOPSE_1999.pdf>. Acesso em: 09/02/2009.

CARUSO, Francisco. Desafios da Alfabetização Científica. In: Ciência, Cultura e Sociedade: a importância da educação científica hoje. Ciclo 21 da Fundação Planetário, set. 2003. Disponível em: <http://cbpfindex.cbpf.br/publication_pdfs/ cs01003.2006_12_08_10_39_34.pdf>. Acesso em: 22/11/2008.

CARVAlHO, Anna Maria Pessoa. A pesquisa no ensino, sobre o ensino e sobre a reflexão dos professores sobre seus ensinos. Educação e Pesquisa, São Paulo, v. 28, n. 2, p. 57-67, jul./dez. 2002.

CARVAlHO Anna Maria Pessoa et al. Ciências no ensino fundamental. São Paulo: Scipione, 1998.

CHARAUDEAU, Patrick.; MAINGUENEAU, Dominique. Dicionário de análise do discurso. São Paulo: Contexto, 2004.

CHASSOT, Áttico Inácio. Alfabetização científica e cidadania. In: . Alfabetização científica: questões e desafios para a educação. Ijuí: UNIJUI, 2000.

FOUCAULT, Michel. A ordem do discurso. Aula inaugural no Collège de France de 2 de dezembro de 1970. Tradução de: Laura F de Almeida Sampaio. 6. ed. São Paulo: Loyola, 2000.

KRASILCHIK, Myriam; MARANDINO, Martha. Ensino de ciências e cidadania. São Paulo: Moderna, 2006.

LORENZETTI, Leonir; DELIZOICOV, Demétrio. Alfabetização científica no contexto das séries iniciais. Ensaio - Pesquisa em Educação em Ciências, v. 3, n. 1. jun. 2001. Disponível em: < http://www.fae.ufmg.br/ensaio/v3_n1/leonir.PDF $>$. Acesso em: 22/11/2008.

MORIN, Edgard. Ciência com consciência. Tradução de: Maria D. Alexandre e Maria Alice S. Doria. 11. ed. Rio de Janeiro: Bertrand Brasil, 2008. 
NUERNBERG, Adriano Henrique. Os processos de negociação dos lugares sociais de professora e alunos no contexto da escolarização formal. Educação e Sociedade, Campinas, v. 23, p. 229-243, 2002. Disponível em: <http://www.cedes.unicamp. br>. Acesso em: 22/11/2008.

NUNES, Clarice. Formação docente: permanência do passado nos desafios do presente. In: SOUZA, João Valdir Alves (Org.). Formação de professores para a educação básica: dez anos da LDB. Belo Horizonte: Autêntica, 2007.

ORLANDI, Eni Pulcinelli. Discurso e leitura. 3. ed. São Paulo: Cortez, 1988.

PAVÃO, Antônio Carlos; FREITAS, Denise (Org.). Quanta ciência há no ensino de ciências. São Carlos: Edufscar, 2008.

PÊCHEUX, Michel. Papel da memória. In: ACHARD, Pierre et al. Papel da memória. Tradução e introdução de: José Horta Nunes. Campinas: Pontes, 1999. p. 49-57.

SANTOS, Wildson Luis Pereira; MORTIMER, Eduardo Fleury. Tomada de decisão para ação social no ensino de ciências. Ciência e Educação, v. 7, n. 1, p. 95-111, 2001. Disponível em: <http://www.fc.unesp.br/pos/revista/>. Acesso em: 22/11/2008. 